\title{
Innovative Teaching Strategies in Research Methods for Health Professions
}

\author{
J. E. Leone and S. Maurer-Starks \\ Northeastern University
}

\begin{abstract}
The purpose of this article is to assist the health educator in teaching and creating innovative methods for facilitating research. A brief background and discussion of the research process is presented followed by how and why research is directly applicable in health professions. A variety of methods and strategies are presented in an overall format of the research process. Lastly, practical application of the strategies presented in this article is discussed.
\end{abstract}

(C) 2007 Californian Journal of Health Promotion. All rights reserved.

Keywords: survey, best-practice, scholarship, grant

\section{Introduction/Background}

Teaching an innately human trait or concept seems like it would be an easy task. When the term research is brought-up in discussion, educators tend to scramble for creative and effective methods to teach these concepts. The concept of research as an innately human trait is grounded in the day-to-day processes we employ to make decisions ranging from simple to complex. For example, if a person is attempting to cross a busy intersection at midday, the process of research is acutely active. First, the simple research question one may pose is "how will I cross the street?" An alternative question may be "where should I cross; here or maybe at another intersection?" When a decision is rendered as to how to approach the simple process of crossing the street, one must then collect and process data. By data, we mean signals that may alert us if the time is appropriate (i.e., safe) to cross. Traffic lights, walking signals, volume of cars, speed of oncoming traffic, other people, sounds, and a host of other variables must be considered prior to taking action (i.e., crossing).

When these "data” are analyzed appropriately, we make a decision about when and how to cross the street, be it running or a casual saunter. Upon successfully crossing the street, we have an opportunity to assess what worked and what did not, such as not crossing when the time may have been most appropriate (Type I errors) or crossing when one should not have (Type II errors). Of course, one always runs the risk of having a "fatally" flawed approach if the research process is not well-thought-out, such as being terminated by an on-coming automobile!

The latter example is of course something most of us will take for granted. You may be asking, "Who cannot cross a street." When we challenge students to "think" like a researcher, these everyday mundane events become living examples of how to best "approach" life's questions through analytical, systematic, and naturalistic inquiry. The purpose of this article is to present creative and innovative methods when educating students on healthcare research.

\section{The Value of Teaching and Incorporating Research into Health Curricula}

Babbie (2001) notes science as a way of "knowing." From processes resulting from scientific and social inquiry, a method of inquiry and ways of learning and knowing become apparent. Obstacles to this process include: personal bias, misconceptions, and sloppy or erroneous methods of observation (Babbie, 2001). Ultimately, knowing leads to truth, and ultimately the value we place in those truths.

Health professionals have made strides to provide information and services to at-risk 
populations. How to best go about meeting health service objectives and criteria can best be evaluated using research and methods of assessment (Neutens \& Rubinson, 2002; Dignan, 1995). Being that health educators borrow from many different professions, all professionals are inherently involved in the research process (Neutens \& Rubinson, 2002).

An argument often voiced in undergraduate and even some graduate curricula is "how much research should be taught.” Is our main goal in any curriculum to turn-out quality researchers? The answer is a resounding "yes" and "no." While it is important to train the next generation(s) of health researchers to seek-out new health knowledge in order to advance standard of care, the realistic approach is to prepare everyone to use research assuring that everyone can positively impact standard of care (Babbie, 2001). Evidence-based medicine is a strong reality, which extends into all areas of healthcare, such as health education, public health, health promotion, and community health approaches (Glanz, Rimer \& Marcus-Lewis, 2002). Incorporating research in the undergraduate curriculum allows students to gain the knowledge and skills to learn the research process, not to conduct it per se, but, rather to use research to bridge the gap between knowledge and critical decision-making.

The graduate level carries with it a new set of expectations. The value of research at the graduate level involves a continuation of the "skills" gained from undergraduate studies; however, higher levels of critical thinking and use of research are to be expected. Graduate programs often present various "tracks" a student may follow. A traditional route has been the masters or doctoral thesis/dissertation. Recent trends have included research papers, community-based projects, and needs assessments. Value in these experiences is high, allowing students to "discover" their niche where they can make the greatest impact. Using research as well as creating new research ideas is an academic value that will continue to enhance quality healthcare as sociocultural values and needs constantly evolve (Babbie, 2001).

\section{Traditional Approaches to Teaching Research Methods}

The traditional approach to teaching research methods has been sequential and systematic. Each part of a research design carries with it a purpose and function, of this there is no doubt; however, the approach is what can change so as to accommodate those that may not be sequential learners. Being able to demonstrate science and research as a dynamic process often proves to be invaluable (Neutens \& Rubinson, 2002). Oftentimes, when research is approached in the classroom, the static "core" (see Figure 1) is stressed, leaving little emphasis on the nature of applied research concepts (Arnold, Gansneder \& Perrin, 2005).

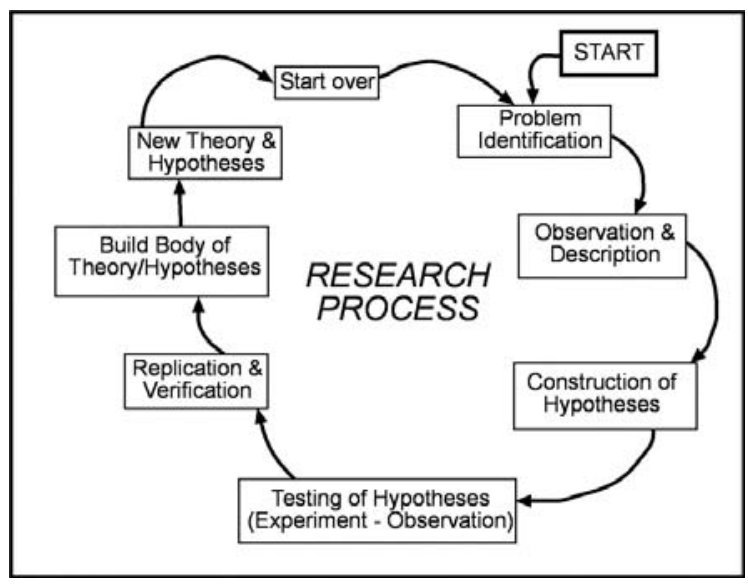

Figure 1

Flow-chart of the basic research design process 


\section{Innovative Teaching Strategies for Teaching} Research Methods in Health Professions

The reflection of research in the classroom needs to address the dynamic nature of the research process in real-life. The basis for using science to improve professional practice and overall quality of life needs to form the foundation in any research course. Assisting students in appreciating the various steps of this dynamic process should be the ultimate goal of the educator. The following presents strategies to assist the educator in this process.

\section{Stage 1 - Masonry 101: Laying a Solid Foundation for Research}

The groundwork for teaching research begins by delivering of the "materials" needed to start the process. Often, we have used the approach of house building as a real-world analogy. Selection of an appropriate "site" to build is similar to deciding a topic to research. Delivering of materials to the site is not unlike seeking-out references and supporting literature relative to the topic. The following discusses a foundational approach.

Activity Approach \#1 - Mapping it out

- Start a class by having students use index cards to write down at least 5 to 10 ideas they have been thinking about or have noticed in practical experiences.

- After ideas have been generated, have students switch the index cards with each other to either add content to the ideas, or generate a new idea (i.e., a new index card).

- At the conclusion of three rounds of trading index cards, have a student volunteer to write the topics on a white board, chalkboard, etc. This will help others to appreciate and visualize all of the ideas.

- Alternative approach: this may be done using a "chat feature" or "discussion board" on a web-based platform.

\section{Main Goal:}

Sharing of ideas and synthesizing an array of topics will help to stimulate thought and discussion versus simply having a person decide in isolation or with only an advisor.

\section{Activity Approach \#2 - Steering the ship} information navigation

- Students will learn how to navigate a library and its resources concerning finding and reviewing research literature.

- The time needed for this activity is relatively time-efficient (one class period).

- The instructor needs to contact the appropriate person in the library/media services to present this topic (the instructor may need to do this in the absence of this person).

- The class should be facilitated in a room with computer (internet) access for each student (numbers will vary).

- Explain to the students that the purpose of the lesson is to identify various research search engines based on topics of interest. The instructor/facilitator should take students through a working example so as to familiarize them with all aspects of a valid search.

- Based on a topic of interest, students should be able to demonstrate a favorable outcome (proficiency) by generating a list of 5 to 10 peerreviewed research citations.

\section{there!}

\section{Activity Approach \#3 - Getting out}

- Have students plan to attend a research conference, symposium, or consortium.

- This does not have to be expensive, just well planned.

- Many schools have funding available for graduate students (and some undergraduates) to pursue for professional development. This may include attendance a local, state, regional, and national conference. Not all expenses may be covered, but the exposure in these settings is often invaluable.

- For those who do not have the financial means to attend a conference, seek 
opportunities at the college/university level for student-based research fairs or symposia. These are great opportunities to see what is going-on in various academic disciplines. Opportunities to talk to presenters may help refine one's topic or ideas.

- To facilitate an organized approach to this, the research course instructor can assign a "research bingo" activity. List major concepts related to research in health education and promotion on "bingo" cards. The goals of the activity are to seek-out these concepts by attendance, interactions, or simple factfinding activities.

- For example, one bingo square may read, "Find a researcher who conducted corporate health promotion research." Have the researcher(s) verify you spoke with them (i.e., signatures).

- The instructor may challenge students to compete or a reflection of their paper may be included as part of a class assignment.

\section{at it!}

Stage 2 - Climbing the Steps: Having a go

Activity Approach \#1

Often, students are torn between the decisions of whether to pursue a quantitative, qualitative, or mixed method approach to their research question. Obviously, this needs to be guided by the nature of the research question(s)/hypothesis(es) (Isaac \& Michael, 1997). One approach to helping students appreciate this latter point and the overall intent of each type of approach is through debate. The following discusses a fun approach to this rudimentary process.

\section{Quantitative/Qualitative Debate:}

- Each student will be placed on a team and will either defend the qualitative or quantitative method of research (an additional group may be assigned for a mixed-methods approach).
- Students will participate by finding relevant sources/examples to back-up their arguments for each point.

- All students have to actively take part in the debate format.

- Each side will be given the opportunity to make opening remarks, rebuttal to the opposite sides arguments, and finally closing remarks.

- The overall winner of the debate will be determined by the course instructor or by class consensus.

\section{Activity Approach \#2}

\section{Hypothesis/ Research Question Development:}

This activity involves thematic mapping or concept mapping. Students can be encouraged to approach this activity with either an inductive approach or deductive approach depending on the nature of the research focus.

\section{Inductive Approach}

- Students who identify the nature of their research as inductive (e.g., qualitative designs), will likely start with the discussion of a phenomenon or several other qualitative traditions (Creswell, 1998).

- Using large poster board size paper, chalkboards, or white boards, have students list all related concepts to the phenomenon or naturalistic topic of inquiry.

- In a second round (following the initial topic generation activity), have the students discuss each point to keep or exclude. Students may decide to vote on this process or develop their own.

- A new "list" is generated with identifiable "themes" emerging.

- At the end of these processes, students should be able to identify several themes or lines of inquiry by which to base their qualitative/ naturalistic inquiry. Identified themes may serve as the basis for research questions to be used in indepth interviews, ethnographies, or focus group approaches. 
- This can be modified using a web-based approach as well (chats, discussion boards, synchronous discussions).

\section{Deductive Approach}

- Students identifying the nature of their research as deductive (e.g., quantitative designs), are encouraged to generate very specific (target) questions to empirically test.

- In groups, using all available questions (students should prepare questions prior to the activity from peer-reviewed database searches), all topics are listed using boards, note cards, or other media.

- Various processes of synthesis and elimination (e.g., nominal group process, Delphi technique) can be used to identify core research questions/hypotheses to empirically test.

- This can be modified using a web-based approach as well (chats, discussion boards, synchronous discussions).

\section{Activity Approach \#3}

Building the study, testing research questions, and conducting interviews at the graduate or undergraduate levels should be carefully planned. Use of a pilot test can be very useful (Dignan, 1995). Many approaches in the health sciences are survey-based (Neutens \& Rubinson, 2002). The classroom is a great setting to test hypotheses and research questions, particularly when using a survey-based approach (Alreck \& Settles, 1994). Qualitative designs as with interviews or focus groups can also be tested using this pilot approach (Borg \& Gall, 1983; Reason \& Bradbury, 2006).

- Have the class distribute their surveys/interview questions to other classmates. Allow for one day (class) for the survey/questions to be taken and evaluated by classmates.

- Surveys should be distributed anonymously to avoid potential bias.

- Evaluation of surveys should be a. timed, b. commented on, c. taken, and d. returned.
- Using one class period, a list of general comments and suggestions should be generated and listed on a board, poster paper, or online web-based platforms.

- As each comment/point is discussed and presented in class, students should be encouraged to take notes and make comments on their surveys/research questions (hypotheses).

\section{Stage 3 - Cement anyone? Putting the pieces together}

Becoming the tour guide in a research class may present a challenge for the instructor. We want the students to embrace the excitement of the research process, yet at the same time, we may hastily "jump-in.” Solving critical issues through critical thinking and decision-making is what pulls this process together. A systematic approach is only as useful as training wheels on a bicycle; eventually they need to be taken off. Apprehension usually exists on both ends; that is the student and the instructor! The essential cement in this process is confidence. The next activity will discuss ways by which to enhance student confidence.

\section{Activity Approach}

- Instructors should consider the necessary content to lay the foundation. A full semester may give great detail of the research process, yet limit the practicality of doing it.

- Review your course content and decide how many classes/weeks will be dedicated to lecture content. Can the lecture content be replaced with book/journal readings?

- For those instructors worried about students actually reading the materials, assign discussion facilitators for content areas. Designing a simple rubric for the quality of the facilitation as well as the quality of participant contributions to the discussion is a relatively timeeffective method. This method assures less Socratic methods of unidimensional facilitation and spawns a multi-dimensional discussion (i.e., active learning).Use the remaining 
course time to allow students to work on their respective sections; yes, in class! Have students work in groups to encourage collaboration and group think tanks. Activities may include using library services, internet searches (if wireless laptop technologies are available), peer critiques, and actual writing time.

- Schedule time blocks in class to meet with each student or group of students to discuss and evaluate progress. This also free's up the instructor's time to evaluate overall progress of student research outside of class time versus details that can be addressed in class.

- On-demand or immediate feedback is enabled using this method. A simple change in class planning can make the most of class time, while maximizing productivity for both the student and instructor.

\section{Stage 4 - Academic Mapquesting your work: where to go from here?}

After volumes of revisions and adjustments to the research manuscript, students may be left with an empty feeling of, "now what?" Close communication with the course instructor or research advisor should determine whether or not a research project is publishable. Not everything is publishable! There are, however, several avenues to explore concerning representation of the student's work and efforts (Arnold, Gansneder \& Perrin, 2005). A planned and unplanned approach follows.

\section{Activity Approach}

\section{Planned:}

- Have students identify five possible journals and five conferences/symposia to research.

- Alert students to identify the mission/vision of the academic journal/publication, target audiences, types of reports, publishing timeframes for submission, acceptance rates, and any other relevant information.
- Similarly, have students' research conferences and symposia for themes and types of proposals that may be included in the programming.

- Ask students to develop "reviewer checklists" for evaluating types of research that may be submitted. Students may then submit an abstract of their work to committees of three other students to undergo a "blind review." If other faculty are willing, they may also be solicited to review student work.

- This will help students to plan and identify possible avenues for publication and presentation to represent their hard work and efforts. Targeting a journal or conference, however; should not be the focus of this activity!

\section{Unplanned:}

- Sometimes things do not go as planned. A flaw in the research design or factors beyond the researcher's control may confound results. So, scrap the project and move on right? Wrong! There are many things to be learned from others mistakes, ask any inventor! There are many avenues to pursue for representing your work, even if it did not go off as planned. Examples include:

- Have students consider submitting to a campus-sponsored research event/ symposium

- Faculty may establish a research showcase session to demonstrate student work.

- Find the good in a project and discuss limiting factors.

- Consider an editorial in the local or school newspaper discussing the research intent.

- REVIEW...REVISE...REVIEW...REV ISE...REVIEW...REVISE!

Stage 5 - Blood, sweat, tears, and toner cartridges: future applications

Many research courses have the ultimate goal of teaching the research method; however, several only take it to the point of completion of the project while glossing over other key features of 
the research process. Because of time constraints and limited credits, students are often left to their own devices to make sense of grant writing, networking for potential collaboration, etc. Incorporating some activities in the research course may help prime the student to spend less time seeking and more time doing.

\section{Activity Approach}

- Challenge students to develop a timeline and rationale for their research. Focus on concepts such as realistic timeframes and sustainability of research. Have students vote if timelines and rationales are appropriate.

- Collaboration and funding go hand-inhand in terms of research sustainability. Have students' set-up three 30-minute interviews with professionals across disciplines (one in their own and two outside). Have students bring a one-page research summary to receive feedback on their approach.

- In terms of funding, students should identify three grant sources (one schoolbased, one foundation, and one national/government). Have students attempt to draft a grant proposal based on these guidelines. This can be done throughout the semester. Students can also be challenged to develop their own "grant" and specify their own criteria.

\section{Practical Applications}

Our intent is for these strategies to stimulate thought and creativity for the instructor challenged with teaching research in a variety of settings. Real-life applications and scenarios have been presented so as to connect the research process with everyday practice. Overcoming the "stigma" of research being a boring but necessary course is possible. A course and its content is only as good as how it is presented. Boring activities and Socratic methods of lecture likely yield bored and unchallenged students. Incorporating multiple strategies that are well-planned before the semester begins will challenge the student and avoid the status quo.

Anecdotal feedback from students concerning these activities has been positive. Each time an activity is presented, the instructor needs to be prepared to learn and modify as needed. Using activity assessments can make this process easier. Best-practice in the classroom will lead to evidence-based clinical and practical decisions for the up-and-coming students of health education and health promotion.

\section{Summary}

Research can be fun, exciting, and fascinating. A feeling of accomplishment, satisfaction, and pride can be the result of contributing to the "greater cause" of our "way of knowing." Research is a complex, exacting, and complex process that yields the ultimate reward of truth or at least a path leading to it (Bailey, 1997). Researching how we teach research is a good start for most academians, practitioners, and students alike. A well-prepared student will likely contribute in some manner whether understanding how to approach a comprehensive needs assessment, conduct feasibility studies for a health promotion concept, or when conducting research to advance the health education's overall body of knowledge.

\section{References}

Arnold, B. L., Gansneder, B. M., \& Perrin, D. H. (2005). Research methods in athletic training. Philadelphia, PA: F. A. Davis Company.

Babbie, E. (2001). The practice of social research (9th ed.). Belmont, CA: Wadsworth Thomson Learning.

Bailey, D. M. (1997). Research for the health professional: a practical guide (2nd ed.). Philadelphia, PA: F. A. Davis Company.

Borg, W. R., \& Gall, M. D. (1983). Educational research: an introduction (4th ed.). New York. Longman. Creswell, J. W. (1998). Qualitative inquiry and research design: choosing among five traditions. Thousand Oaks, CA: Sage Publications. 
Dignan, M. B. (1995). Measurement and evaluation of health education. Springfield, IL: Charles C. Thomas Publishers.

Glanz, K., Rimer, B. K., \& Marcus-Lewis, F. (2002). Health behavior and health education: Theory, research, and practice (3rd ed.). San Francisco, CA: Jossey-Bass.

Isaac, S., \& Michael, W. B. (1997). Handbook in research and evaluation: for education and the Behavioral sciences (3rd ed.). San Diego, CA: EdITS.

Neutens, J. J., \& Rubinson, L. (2002). Research techniques for the health sciences (3rd ed.). San Francisco: Benjamin-Cummings.

Reason, P., \& Bradbury, H. (2006). Handbook of action research. Thousand Oaks, CA: Sage Publications.

Author Information

James E. Leone, Ph.D., LAT, ATC, CSCS*

Bouvé College of Health Sciences

301 T Robinson Hall

Northeastern University

Boston, MA 02115

Ph.: 617-373-5536

Fax.: 617-373-5920

Email: jleoneatc@yahoo.com

S. Maurer-Starks, Ed.D., ATC

Bouvé College of Health Sciences

Northeastern University

Boston, MA 02115

* corresponding author 